\title{
Is Computer-Assisted Aminoglycoside Dosing Managed by a Pharmacist a Safety Tool of Pharmacotherapy?
}

\author{
E. DVOŘÁČKOVÁ ${ }^{1,2}$, P. PÁVEK ${ }^{3}$, B. KOVÁČOVÁ ${ }^{4}$, J. RYCHLÍČKOVÁ $^{5,6}$, \\ O. SUCHOPÁR ${ }^{7}$, M. HOJNÝ ${ }^{2}$, J. D. TEBBENS ${ }^{8}$, J. VLČEK ${ }^{1}$
}

${ }^{1}$ Department of Social and Clinical Pharmacy, Faculty of Pharmacy, Charles University, Hradec Králové, Czech Republic, ${ }^{2}$ Hospital Pharmacy, Institute for Clinical and Experimental Medicine, Prague, Czech Republic, ${ }^{3}$ Department of Pharmacology, Faculty of Medicine, Charles University, Hradec Králové, Czech Republic, ${ }^{4}$ Department of Clinical Pharmacy, Teaching Hospital, Plzeň, Czech Republic, ${ }^{5}$ Department of Pharmacology, Faculty of Medicine, Masaryk University, Brno, Czech Republic, ${ }^{6}$ Department of Clinical Pharmacy, Masaryk Memorial Cancer Institute, Brno, Czech Republic, ${ }^{7}$ Independent consultant, Drugagency a.s., Prague, Czech Republic, ${ }^{8}$ Department of Biophysics and Physical Chemistry, Faculty of Pharmacy, Charles University, Hradec Králové, Czech Republic

Received September 3, 2019

Accepted September 16, 2019

\section{Summary}

This pilot prospective study verified the hypothesis that use of computer-assisted therapeutic drug monitoring of aminoglycosides by pharmacists leads to better safety therapeutic outcomes and cost avoidance than only concentration measurement and dose adjustments based on a physician's experience. Two groups of patients were enrolled according to the technique of monitoring. Patients (Group 1, n=52) underwent monitoring by a pharmacist using pharmacokinetic software. In a control group (Group 2, $n=11$ ), plasma levels were measured but not interpreted by the pharmacist, only by physicians. No statistically significant differences were found between the groups in factors influenced by therapy. However, the results are not statistically significant but a comparison of the groups showed a clear trend towards safety and cost avoidance, thus supporting therapeutic drug monitoring. Safety limits were achieved in $76 \%$ and $63 \%$ of cases in Groups 1 and 2, respectively. More patients achieved both concentrations (peak and trough) with falling eGFR in Group 1. In present pilot study, the pharmacist improved the care of patients on aminoglycoside therapy. A larger study is needed to demonstrate statistically significantly improved safety and cost avoidance of aminoglycoside therapy monitoring by the pharmacist using pharmacokinetic software.

\section{Key words}

Therapeutic drug monitoring • Aminoglycosides • Pharmacist • Nephrotoxicity • Pharmacokinetics

\section{Corresponding author}

E. Dvořáčková, Department of Social and Clinical Pharmacy, Faculty of Pharmacy, Heyrovského 1203, Hradec Králové, 500 05, Czech Republic. E-mail: eliskadvorackova@seznam.cz

\section{Introduction}

Monitoring of aminoglycoside (amikacin and gentamicin) therapy is essential to ensure optimal therapy and prevent their toxicity, in particular nephrotoxicity and ototoxicity. Based on literature data, nephrotoxicity occurs in 10-25\% of treated patients (Lerner et al. 1977). The recognized risk factors for nephrotoxicity include older age, preexisting renal failure, concomitant use of nephrotoxic drugs, therapy duration, and higher through levels as well as dehydration (Lopez-Novoa et al. 2011). Clinical manifestations of nephrotoxicity (Chvojka et al. 2010) are reversible non-oliguric acute renal failure with a slow rise in serum creatinine levels becoming apparent within 7-14 days of aminoglycoside therapy initiation (Humes 1988). As for ototoxicity, its incidence depends 
on therapy duration occurring as it does in $25 \%$ of treated patients (Lerner et al. 1977); however, according to Alharazneh et al. (2011) the real incidence in clinical practice is underestimated. On the other hand, neuromuscular toxicity is an uncommon adverse effect of aminoglycoside therapy, and is potentiated by diseases such as myasthenia gravis, concomitant administration of muscle relaxants (Kohoutová et al. 2018) and hypocalcemia (Wieske et al. 2015).

Aminoglycoside therapeutic drug monitoring (TDM) can be performed using several methods: trough level measurement only, peak and trough level measurement, use of nomograms, or Bayesian systems. Mere measurement of plasma aminoglycoside levels (as a key component of TDM) without adequate interpretation is insufficient. Interpretation of measured plasma drug levels by the clinical pharmacist or clinical pharmacologist allows to determine the optimal dosage and dosing intervals for each individual patient (Slanař and Perlík 2015). Numerous pharmacokinetic software applications have been developed for TDM, with all of them employing the Bayesian approach combining a population-based model with the current pharmacokinetic or physiological data of the individual patient (body height, body weight, serum creatinine, and age) to define the best dosing regimen. Crucial for use of pharmacokinetic software is very good knowledge of pharmacology and pharmacokinetics.

Recently published TDM studies with aminoglycoside levels managed either by a clinical pharmacist or by a clinical pharmacologist showed reduced mortality rates, nephrotoxicity, length of hospital stay and confirmed cost-effectiveness of TDM for the health care system (Destache et al. 1990, Streetman et al. 2001, van Lent-Evers et al. 1999). While several studies have documented the cost effectiveness of aminoglycoside TDM (Slaughter and Cappelletty 1998, Bond and Raehl 2005, Franson et al. 1988), little information is still available to quantify the impact of pharmacist-led TDM with pharmacokinetic software versus interpretation of drug levels by physicians based only on their experience (Lenert et al. 1992). Published reports suggest that peak therapeutic drug concentrations in blood are achieved in only $25-60 \%$ of patients (Franson et al. 1988, Sveska et al. 1985). The ability of physicians to adjust the doses after reviewing the drug concentrations measured is poor. It was found that physicians failed to take action in at least $40 \%$ of cases whereby the measured drug levels mandated a change in dosing (Arroyo et al. 1986, Anderson et al. 1976).

The objective of this study was to verify the hypothesis that use of computer-assisted TDM of aminoglycosides by the pharmacist with experience in TDM leads to better therapeutic outcomes and cost avoidance compared with only measurement of levels and dose adjustments based on a physician's experience.

\section{Methods}

\section{Study design and study period}

This study was a pilot prospective study of TDM by a pharmacist conducted from March 2016 to January 2017.

\section{Setting}

The study was conducted at the Prague-based Institute for Clinical and Experimental Medicine (IKEM), a highly specialized healthcare facility and research center in the Czech Republic with 315 beds. The Institute has an independent department of clinical pharmacy located within the compound. The clinical pharmacist interprets $80 \%$ of the antibiotic (vancomycin, amikacin, gentamicin) levels measured at the hospital. Therapeutic drug monitoring involves estimation of the initial dosing regimen relative to the clinical condition and patient characteristics such as age, body weight, renal function, and concomitant drug therapy. The primary goal of TDM is to suggest proper medication and to optimize clinical outcomes of patients in various clinical conditions using appropriate levels of each drug. The interpretation of each individual physician is entered into the hospital information system.

\section{Patient selection}

Included in our study were all patients admitted to hospital between March 1, 2016 and January 31, 2017. The hospital information system was used to identify patients receiving amikacin or gentamicin therapy. Only patients older than 18 years were enrolled if they were receiving an aminoglycoside for the treatment of infection for at least five days. Patients were excluded if they were receiving the prophylactic amikacin or gentamicin, the expected therapy duration was less than five days, or were on peritoneal dialysis or hemodialysis (HD). We used the following medication administered as intravenous infusion (Amikacin B. Braun ${ }^{\circledR} 10 \mathrm{mg} / \mathrm{ml}$ infusion solution or Gentamicin Lek ${ }^{\circledR} \quad 80 \mathrm{mg} / 2 \mathrm{ml}$ infusion solution). All included patients were divided into 
two groups: in Group 1, TDM was carried out with the clinical pharmacist interpreting all aminoglycoside levels measured whereas, in Group 2, aminoglycoside levels were also measured but interpreted by physicians. In Group 1, the clinical pharmacist provided interpretation of antibiotic levels using pharmacokinetic software MwPharm version 4.0 (MEDIWARE, Prague, Czech Republic). Nephrotoxicity, analyzed in both groups, was defined as an increase in serum creatinine levels by $26.4 \mu \mathrm{mol} / 1(0.3 \mathrm{mg} / \mathrm{dl})$, which is the first grade in the classification of acute kidney injury (AKI) based on creatinine concentration (Levi et al. 2013) or 50-100\% over baseline (creatinine levels on Day 1 of therapy) (Kahlmeter and Dahlager 1984). Chronic renal failure was defined as an estimated glomerular filtration rate (eGFR, CKD-EPI equation) below $60 \mathrm{ml} / \mathrm{min}$ (Levey et al. 2011). Serum creatinine levels were measured using an enzymatic spectrophotometric method (Roche Diagnostics GmbH instrument, Germany). Serum creatinine levels on Days 1 and 5 of therapy and the first and the last days of therapy were compared between both groups. Furthermore, the creatinine levels on Day 1 of therapy were compared with chronic creatinine levels determined before hospitalization. In addition, both groups were compared with respect to the duration of antibiotic therapy, total cumulative doses and cumulative doses to Day 5. These variables have been recently documented to correlate with aminoglycoside associatednephrotoxicity (Cimino et al. 1987, Mathews and Bailie 1987, Avent et al. 2011). Therapy duration was defined as the time from Day 1 to the last day of aminoglycoside therapy. The half-life of aminoglycosides in renal cortex tissue is approximately $100 \mathrm{~h}$, therefore repetitive dosing of aminoglycosides may result in renal accumulation and toxicity (Gonzalez and Spencer 1998). For this reason, we monitored the risk factors associated with aminoglycoside nephrotoxicity (for furosemide, vancomycin, angiotensin-converting enzyme inhibitors, angiotensin receptor blockers, nonsteroidal antiinflammatory drugs, amphotericin, cyclosporine, tacrolimus, acyclovir, and iodine contrast media).

\section{Patients' records}

The following clinical or demographic data were collected: age, sex, body weight, height, body mass index (BMI), serum creatinine levels before hospitalization on Days 1 and 5 and on the last day of therapy, therapy duration, pathogen, site of infection, minimal inhibitory concentration of the pathogen, diabetes mellitus in personal history and transplantation status. As for biochemical markers, the parameters we followed included liver enzymes, electrolytes (sodium, potassium, magnesium), acid-base status and serum albumin levels.

\section{Plasma antibiotic concentration analysis}

Plasma aminoglycoside concentrations were measured in both groups on Day 2 of therapy and on Day 5, if therapy lasted Day $10 \pm 2$, Day $15 \pm 2$, Day $20 \pm 2$, Day $25 \pm 2$. We analyzed the through concentrations before the second dose (minimal concentration) and the peak concentrations $30 \mathrm{~min}$ after the second dose. The real duration of infusion was recorded. We divided patients by estimated glomerular filtration rate (eGFR). We also recorded whether the target trough and/or peak concentrations had been achieved in eGFR measurements. Glomerular filtration rate was estimated using serum creatinine concentrations on Day 1 of therapy and the CKD-EPI equation. The therapeutic range is below $2 \mathrm{mg} / 1$ for safety and above $10 \mathrm{mg} / 1$ for efficacy for gentamicin and below $1 \mathrm{mg} / \mathrm{l}$ and above $20 \mathrm{mg} / \mathrm{l}$, respectively, for amikacin.

\section{Pharmacokinetic analysis}

In Group 1, pharmacokinetic analysis was carried out using the pharmacokinetic software with a two-compartment pharmacokinetic model. The serum antibiotic levels (trough and peak) as well as patients' demographic data (age, sex, body weight and height) and serum creatinine levels were used for pharmacokinetic predictions. For their recommendations regarding optimization of aminoglycoside dosing, the pharmacist used not only pharmacokinetic software but, also, information about each patient's clinical status as well as knowledge about pharmacokinetics and pharmacology. The recommendations included the dose, dosing interval and the date of measurement of levels of other drugs in each patient. Next, the pharmacist discussed their recommendations for order optimization with the prescribing physician. All recommendations were subsequently entered in the electronic request system. In Group 2, no pharmacokinetic analysis was undertaken, with physicians only measuring the drug levels to adjust the dose and dosing interval based on their experience.

\section{Cost avoidance analysis}

Cost avoidance was calculated as the difference between the net cost of HD of treatment of an adverse effect of therapy with aminoglycosides without 
monitoring by the clinical pharmacist and costs to cover the clinical pharmacist service in 0.2 full-time equivalent (FTE). To calculate cost avoidance, we used retrospective data covering a 4-year period (2013-2016) in our hospital where 300 patients had been treated with an aminoglycoside, which showed that healthcare without TDM was associated with the following events:

- In 7 patients, HD was required for nephrotoxic antibiotic therapy over the 4-year period an average of 2 patients/year. Acute kidney injury causality was evaluated by a nephrologist.

- In total, $29 \mathrm{HD}$ sessions were performed on average $4 \mathrm{HDs}$ /patient.

\section{Statistical analysis}

The demographic and clinical data, and target levels achieved were analyzed using descriptive statistics and compared between the two patient groups. The variables (age, gender, serum creatinine levels, therapy duration, through concentrations, presence/absence of diabetes mellitus, status after transplantation, type of antibiotic, cumulative dose, kidney or liver failure, electrolyte levels, albumin levels and acid-base status) were selected on the basis of literature data for their impact on aminoglycoside-associated nephrotoxicity (Fernández de Gatta et al. 1996). Two-tailed $t$-tests were used for continuous variables. For dichotomous variables, Pearson's chi-square test was used. Differences were considered significant at a level of $\mathrm{p}<0.05$.

\section{Results}

\section{Patient demographics and characteristics}

Overall, data of 63 patients were collected in the study. The patients enrolled were divided into two groups according to TDM.

Group 1: patients in whom aminoglycoside therapy was monitored by a pharmacist and performed by TDM using a pharmacokinetic program.

Group 2: patients in whom aminoglycoside therapy was not monitored by a pharmacist and the management of the treatment (dose regimen) was conducted exclusively by the attending physician.

Group 1 included 52 patients and Group 2 included 11 patients. Demographic characteristics of the study groups are shown in Table 1 and their clinical characteristics in Table 2. This study demonstrated no statistically significant differences in demographic data and clinical characteristics between Groups 1 and 2 .
The incidence of chronic renal failure was similar in both groups. Table 3 shows factors influenced by TDM carried out by the pharmacist or by physicians. No statistically significant differences in factors influenced by TDM such as serum creatinine levels on Day 5 or on the last day of therapy, cumulative dose and therapy duration as well as the number of drug level measurements, and \% of target levels achieved were found between the groups. Trough concentrations were achieved in $76 \%$ and $63 \%$ of cases in Groups 1 and 2, respectively. Peak concentrations were achieved in $63 \%$ of patients in Group 1 and $54 \%$ of Group 2 patients. In Tables 4 and 5 is summarized the distribution eGFR trough and peak concentration in Groups 1 and 2. More patients achieved both concentrations (peak and trough) with falling eGFR in Group 1.

\section{Pharmacoeconomic analysis}

The pharmacist's activity thus prevented on average $8 \mathrm{HD}$ sessions in 2 patients during the pilot project. We assume that the number of exposed patients was consistent throughout the years (75 patients) and, also, that TDM was not performed by the pharmacist. Since the incidence of HD sessions averaged 2 patients per year, one can assume that the incidence of adverse effects of the selected aminoglycoside requiring dialysis was $2.7 \%$ per patient/year (2/75). Based on current data, it can be supposed that the costs of $8 \mathrm{HD}$ sessions (3491 CZK/1 HD) are $27928 \mathrm{CZK} /$ year (1110 EUR/year), i.e. $4200 \mathrm{EUR}$ in total. The costs incurred by the pharmacist 0.2 full-time equivalent (FTE) per year are $80000 \mathrm{CZK}$ (2962 EUR/year). The difference is negative (-1852 EUR/year). The costs of the pharmacist are higher than the net cost of HD.

\section{Discussion}

The present pilot study was conducted in our hospital to compare the effect of two different approaches to aminoglycoside therapy monitoring. Our objective was to obtain and report new data associated with TDM by the pharmacist to assess its impact on safety and cost avoidance. We compared our results with those of international centers. As per our study design, in Group 1, the pharmacist did TDM whereas, in Group 2, the physicians were responsible for plasma aminoglycoside level measurement and interpretation of the results without pharmacokinetic software. Based on the positive findings from previous studies (Destache et al. 1990, Touw et al. 
Table 1. Demographic data of patients enrolled in the study - continuous variables.

\begin{tabular}{lccccc}
\hline Characteristics & $\begin{array}{c}\text { Mean in Group 1 } \\
\text { (therapeutic drug } \\
\text { monitoring by a } \\
\text { pharmacist) } \\
\text { (52 patients) }\end{array}$ & SD & $\begin{array}{c}\text { Mean in Group 2 } \\
\text { (therapeutic } \\
\text { drug monitoring } \\
\text { by physicians) } \\
\text { (11 patients) }\end{array}$ & SD & p-value for -test \\
\hline Age (years) & 61.0 & 11 & 65.3 & 9 & \\
Weight $(\mathrm{kg})$ & 84.6 & 23 & 83.6 & 12 & 0.284 \\
Height $(\mathrm{cm})$ & 172.1 & 13 & 177.5 & 9 & 0.892 \\
BMI $\left(\mathrm{kg} / \mathrm{m}^{2}\right)$ & 30.1 & 19 & 26.5 & 3 & 0.201 \\
Albumin $(\mathrm{g} / \mathrm{l})$ & 29.8 & 5 & 26.5 & 9 & 0.645 \\
Initial creatinine & 90 & 34 & 83 & 203 & 0.442 \\
(umol/l) before & & & & & \\
hospitalization & & & & & \\
\hline
\end{tabular}

BMI - body mass index.

Table 2. Clinical data of patients enrolled in the study - dichotomic variables.

\begin{tabular}{lccc}
\hline $\begin{array}{l}\text { Parameter } \\
\text { (number of patients) }\end{array}$ & $\begin{array}{c}\text { Group 1 } \\
\mathbf{5 2} \text { patients) }\end{array}$ & $\begin{array}{c}\text { Group 2 } \\
\text { (11 patients) }\end{array}$ & $\begin{array}{c}\text { p-value for Chi-square } \\
\text { test }\end{array}$ \\
\hline $\begin{array}{l}\text { Gentamicin } \\
\text { Gender (men) }\end{array}$ & $28(54 \%)$ & $8(73 \%)$ & 0.250 \\
Nephrotoxic co-medication* & $41(79 \%)$ & $8(73 \%)$ & 0.657 \\
Chronic renal failure** & $18(35 \%)$ & $5(45 \%)$ & 0.498 \\
Liver failure*** & $17(33 \%)$ & $4(36 \%)$ & 0.814 \\
Diabetes mellitus & $3(6 \%)$ & $1(9 \%)$ & 0.681 \\
Electrolyte imbalance**** & $24(46 \%)$ & $5(45 \%)$ & 0.966 \\
Status after transplantation & 0 & 0 & ---- \\
Acid-base status & $11(21 \%)$ & 0 & 0.355 \\
\hline
\end{tabular}

*Tacrolimus, vancomycin, furosemide, angiotensin-converting enzyme inhibitors were potentially nephrotoxic co-medication in these patients. ${ }^{*}$ Renal failure was determined by glomerular filtration rate below $60 \mathrm{ml} / \mathrm{min}$. ***Liver failure was defined as liver enzymes elevated 3 times above ULN (upper normal value). ****Electrolyte imbalance was defined as sodium, potassium and magnesium imbalance.

2005, van Lent-Evers et al. 1999, Pinilla et al. 1992) we believe that direct pharmacist involvement in TDM service may help to optimize dosing and timing of concentration measurement, which may translate into improved patient outcomes such as length of hospital stay, clinical cure and incidence of AKI. A total of $83 \%$ of patients receiving aminoglycosides had pharmacist-led pharmacokinetic monitoring, indicating broad pharmacist supervision in our hospital versus $17 \%$ of patients monitored only by physicians. No significant differences between the groups were found in any of the demographic characteristics (age, body weight, height, $\mathrm{BMI}$ ) and two biochemical parameters (albumin levels, serum creatinine before hospitalization). Patients were middle-aged with normal BMI and serum creatinine levels. The proportion of men was higher in both groups. The number of potentially nephrotoxic co-medications (furosemide, vancomycin, angiotensin-converting enzyme inhibitors, angiotensin receptor blockers, nonsteroidal anti-inflammatory drugs, amphotericin, cyclosporine, tacrolimus, acyclovir, iodine contrast media) increasing aminoglycoside nephrotoxicity was the same between the groups, and none was at high risk of nephrotoxicity. In our study, amikacin and gentamicin were compared together because the TDM strategy is identical and both have a nephrotoxic potential. 
Table 3. Parameters influenced by TDM by the pharmacist or by physicians.

\begin{tabular}{|c|c|c|c|c|c|}
\hline Parameter & $\begin{array}{l}\text { Mean in Group } 1 \\
\text { (52 patients) }\end{array}$ & SD & $\begin{array}{c}\text { Mean in } \\
\text { Group 2 } \\
\text { (11 patients) }\end{array}$ & SD & p-values \\
\hline Creatinine on Day 1 of therapy & 103.7 & 54 & 156.6 & 145 & 0.308 \\
\hline $\begin{array}{l}\text { Creatinine on Day } 5 \text { of therapy } \\
(\mu \mathrm{mol} / \mathrm{l})\end{array}$ & 102.4 & 56 & 128.8 & 86 & 0.271 \\
\hline $\begin{array}{l}\text { Creatinine on last day of therapy } \\
(\mu \mathrm{mol} / \mathrm{l})\end{array}$ & 109.8 & 62 & 122.1 & 87 & 0.605 \\
\hline Therapy duration (days) & 10.5 & 6 & 10.2 & 5 & 0.885 \\
\hline $\begin{array}{l}\text { Cumulative dose after } 5 \text { days of } \\
\text { therapy }(\mathrm{mg})\end{array}$ & 2641.9 & 1671 & 2595.5 & 3563 & 0.948 \\
\hline $\begin{array}{l}\text { Cumulative dose after whole } \\
\text { therapy (mg) }\end{array}$ & 5659.12 & 5340 & 5581.1 & 3290 & 0.233 \\
\hline $\begin{array}{l}\text { Number of concentration } \\
\text { measurements }\end{array}$ & 4.73 & 4 & 6.36 & 4 & 0.185 \\
\hline $\begin{array}{l}\text { Number of trough antibiotic } \\
\text { concentrations achieved (\%)* }\end{array}$ & 76 & & 63 & & 0.516 \\
\hline $\begin{array}{l}\text { Number of peak antibiotic } \\
\text { concentrations achieved (\%)* }\end{array}$ & 70 & & 54 & & 0.566 \\
\hline
\end{tabular}

*Not mean values.

Table 4. Achievement (\%) of trough and peak concentration in Group 1 by estimated glomerular filtration rate.

\begin{tabular}{lcccc}
\hline eGFR (ml/min) & $\begin{array}{c}\text { Number (\%) } \\
\text { of patients }\end{array}$ & Trough only (\%) & Peak only (\%) & Trough and peak (\%) \\
\hline$>90$ & $18(35)$ & 11 & 6 & 67 \\
$90-61$ & $14(27)$ & 14 & 7 & 71 \\
$60-30$ & $16(31)$ & 13 & 13 & 50 \\
$<29$ & $4(7)$ & 25 & - & 50 \\
\hline
\end{tabular}

eGFR - estimated glomerular filtration rate.

Table 5. Achievement (\%) of trough and peak concentration in Group 2 by estimated glomerular filtration rate.

\begin{tabular}{lccc}
\hline eGFR (ml/min) & Number (\%) of patients & Trough only (\%) & Trough and peak (\%) \\
\hline$>90$ & $3(27.2)$ & 33 & 67 \\
$90-61$ & $4(36.4)$ & - & 50 \\
$60-30$ & $2(18.2)$ & 50 & 50 \\
$<29$ & $2(18.2)$ & - & - \\
\hline
\end{tabular}

eGFR - estimated glomerular filtration rate.

Another two risk factors increasing the potential for AKI are chronic renal failure and diabetes mellitus. The number of patients with these conditions was identical in either group. While AKI associated with aminoglycoside therapy is reported to occur in 10-25\% of patients, no patient developed aminoglycoside-induced 
AKI in our study (Lerner et al. 1977). The risk of nephrotoxicity depended on the definition used, the patient group studied, concomitant drug therapy and whether TDM had been performed. As the Institute for Clinical and Experimental Medicine is a center specializing in transplant medicine, both of our patient groups included transplant recipients. Our patients did not show any predisposition to nephrotoxicity as well as electrolyte imbalance and acid-base status. No significant between-group differences were found in outcomes influenced by therapy (therapy duration, number of concentration measurements, serum creatinine levels, and cumulative dose). In Group 2, there was a trend towards a higher number of concentration measurements (about one third more) than in Group 1. We hoped that the number of sampling and costs would be reduced by TDM. Chanas et al. (2019) also reported no difference between their groups in terms of a reduced number of TDM-related lab tests ordered.

In Group 1, target trough and peak levels were achieved in $76 \%$ and $70 \%$ of cases, respectively; the respective figures for Group 2 were $63 \%$ and $54 \%$. Although the results are not statistically significant, our comparison of the two groups showed a trend towards higher rates of therapeutic concentrations achieved in patients with pharmacist-led TDM. Previous studies have documented a high prevalence of aminoglycoside underdosing by physicians. Our results are consistent with previously reported data suggesting that peak therapeutic drug concentrations in the blood are achieved in only $25-60 \%$ of patients (Franson et al. 1988, Sveska et al. 1985). Anderson et al. (1976) and Arroyo et al. (1986) found that physicians failed to take action in at least $40 \%$ of cases whereby the drug levels measured mandated a change in dosing. Tables 4 and 5 summarize the distribution of eGFR trough and peak concentration in Groups 1 and 2. More patients achieved both concentrations (peak and trough) with falling eGFR in Group 1. A pharmacist's knowledge of pharmacology and pharmacokinetics of drugs and experience with pharmacokinetics software would eliminate the problem with wrong decisions about aminoglycoside dosing, a fact making our study so unique. A pharmacist then used Bayesian pharmacokinetic software to more accurately determine achieving therapeutic concentrations (Zaske et al. 1982). Our results demonstrated that TDM conducted by a pharmacist using pharmacokinetic software showed a trend towards safe aminoglycoside dosing. The objective of TDM with serum drug concentration is to achieve quick therapeutic success and reduce the costs associated with management of druginduced complications requiring dialysis. In our study, the pharmacist's activity prevented an average of $8 \mathrm{HD}$ sessions in 2 patients during the pilot project. Based on current data, one can assume that the costs of $8 \mathrm{HD}$ sessions are $27928 \mathrm{CZK} /$ year (1110 EUR/year), thus 1110 EUR in total. The costs by pharmacist 0.2 FTE per year are $80000 \mathrm{CZK}$ (2962 EUR/year). The difference is negative (-1852 EUR/year). In their study, Pinilla et al. (1992) also documented no statistically significant benefit resulting from pharmacists recommendations. The median of length of hospital stay for acute kidney injury is 9 days in Czech Republic (IHIS CR 2015). For IKEM, the cost was calculated as $139 \mathrm{EUR} /$ day. For economic analysis, we calculated the costs of dialysis for 2 patients and the cost of hospitalization for acute kidney injury. The result is 3600 EUR. The cost by pharmacist 0.2 FTE per year is 2962 EUR. The cost of hospitalization with dialysis was subtracted from those incurred by the pharmacist service. The final sum is $638 \mathrm{EUR} /$ year in favor of pharmacist service. Pharmacist-led TDM reduced the risk of complications due to more accurate dosing. Hospitals without pharmacist TDM-guided therapy reported more days of hospital stay, the incidence of renal failure was higher by $33.95 \%$ (occurring in 2801 patients) (Nesbit et al. 2001). This pharmaceutical service in clinical practice has the potential to minimize the risks of nephrotoxicity. Each pharmacist intervention was costsaving related to nephrotoxicity (Bond and Raehl 2005). It is important to remember that it is primarily the patients and their quality of life which matter. For this reason, it would be more beneficial to carry out a costutility analysis to show more clearly that HD can negatively affect quality of life, especially in situations where nephrotoxic side effects have a long-term adverse effect on the patient in terms of permanent damage or renal impairment. We decided not to calculate the costs of hospital stay prolongation because the patients were not treated by aminoglycoside. In our study, the increase in costs due to extended hospitalization was not calculated as the patients with aminoglycoside-induced nephrotoxicity had been switched to another antibiotic. Further studies are warranted to define the cost-benefit of this pharmacist service. In our study, the incidence of AKI requiring HD was very low compared with other studies reporting nephrotoxicity in about $10-25 \%$ of patients (Lerner et al. 1977). A plausible explanation is that IKEM is a highly specialized hospital where 
physicians are aware of nephrotoxicity and proper aminoglycoside dosing. Importantly, there was no case of HD due to nephrotoxicity of aminoglycoside therapy in patients with pharmacist-led TDM. Thus, the pharmacist's activity prevented an average of $8 \mathrm{HD}$ sessions in 2 patients during the pilot project.

Although the results are not statistically significant, implementation of a pharmacist led therapeutic monitoring led to a clear safety benefit and cost avoidance trend. Consistent studies have demonstrated that TDM is cost-effective in maximizing antibiotic efficacy and reducing the incidence of toxicity (Bond and Raehl 2005, Venisse and Boulamery 2011). Potential cost savings in the Czech Republic were published for vancomycin, but not an aminolycoside (Venisse and Boulamery 2011). What is also unique about our study is paucity of data on aminoglycoside dosing in transplant patients (liver, kidney, pancreas) was very little published. There is also a rarely published comparison of the two aminoglycoside dosing procedures, empirical by the physician versus dosing by using a pharmacokinetic program (Lenert et al. 1992).

\section{Limitations}

A comparison of our data with results of published clinical trials reporting aminoglycoside nephrotoxicity and cost avoidance is difficult because of unknown differences in risk among the various patient populations treated. Another problem is the definition of nephrotoxicity. Studies used different definitions based on an increase in serum creatinine levels or calculated creatinine clearance. Our group of patients was too small and enrolled in a single site. Regarding cost economic analysis, there was a problem with calculation of not-net costs such as lab costs associated with concentration measurements. In Group 2, concentration measurement was more frequent (by a third) than in Group 1 and involved extra costs, not calculated in our study.

\section{Conclusions}

In our pilot study, no statistically significant differences were found between the groups in factors influenced by therapy such as serum creatinine levels on Day 5 of therapy or on the last day of therapy, cumulative dose and therapy duration and the number of concentration measurements. In Group 1, with pharmacist-led TDM, there were more patients achieving target concentrations. Therapeutic drug monitoring by the pharmacist prevented an average $8 \mathrm{HD}$ sessions in 2 patients during the pilot project. Therapeutic drug monitoring by the pharmacist with pharmacokinetic software improves the quality and safety of the therapeutic process. Pharmacists continue to provide recommendations based on TDM data to improve care. This study highlights the need for further research into pharmacist-led TDM and the impact of pharmacists' recommendations on cost avoidance.

\section{Conflict of Interest}

There is no conflict of interest.

\section{Acknowledgements}

The authors would like to acknowledge the help of their colleagues Kornélia Chrapková, Iva Prokopová, Stanislav Gregor in data collection and David Hačkajlo for creating the software application used in this analysis.

\section{Abbreviations}

TDM, therapeutic drug monitoring; IKEM, Institute for Clinical and Experimental Medicine; HD, hemodialysis; AKI, acute renal injury; FTE, full-time equivalent.

\section{References}

ALHARAZNEH A, LUK L, HUTH M, MONFARED A, STEYGER PS, CHENG AG, RICCI AJ: Functional hair cell mechanotransducer channels are required for aminoglycoside ototoxicity. PloS One 6: 22347, 2011.

ANDERSON AC, HODGES GR, BARNES WG: Determination of serum gentamicin sulfate levels: ordering patterns and use as a guide to therapy. Arch Intern Med 136: 785-787, 1976.

ARROYO JC, MILLIGAN WL, DAVIS J, MITCHELL D: Impact of aminoglycoside serum assays on clinical decisions and renal toxicity. South Med J 79: 272-276, 2011.

AVENT ML, ROGERS BA, CHENG AC, PATERSON DL: Current use of aminoglycosides: indications, pharmacokinetics and monitoring for toxicity. Intern Med J 41: 441-449, 2011.

BOND CAC, RAEHL CL: Clinical and economic outcomes of pharmacist-managed aminoglycoside or vancomycin therapy. Am J Health Syst Pharm 62: 1596-1605, 2005. 
CHANAS T, HOCKMAN R, RICE T, COX-HALL H, MALLOW-CORBETT S, ALEXANDER BT: Clinical and procedural evaluation of a pharmacy pharmacokinetic consult service. J Pharm Pract (in press) 2019. doi: 10.1177/0897190019826484

CHVOJKA J, SÝKORA R, KARVUNIDIS T, RADĚJ J, KROUŽECKÝ A, NOVÁK I, MATĚJOVIČ M: New developments in septic acute kidney injury. Physiol Res 59: 859-869, 2010.

CIMINO MA, ROTSTEIN C, SLAUGHTER RL, EMRICH LJ: Relationship of serum antibiotic concentrations to nephrotoxicity in cancer patients receiving concurrent aminoglycoside and vancomycin therapy. Am J Med $\mathbf{8 3}$ : 1091-1097, 1987.

DESTACHE CJ, MEYER SK, BITTNER MJ, HERMANN KG: Impact of a clinical pharmacokinetic service on patients treated with aminoglycosides: a cost-benefit analysis. Ther Drug Monit 12: 419-426, 1990.

FERNÁNDEZ DE GATTA MD, CALVO MV, HERNÁNDEZ JM, CABALLERO D, SAN MIGUEL JF, DOMÍNGUEZ-GIL A: Cost-effectiveness analysis of serum vancomycin concentration monitoring in patients with hematologic malignancies. Clin Pharmacol Ther 60: 332-340, 1996.

FRANSON TR, QUEBBEMAN EJ, WHIPPLE J, THOMSON R, BUBRICK J, ROSENBERGER SL, AUSMAN RK: Prospective comparison of traditional and pharmacokinetic aminoglycoside dosing methods. Crit Care Med 16: $840-843,1988$.

GONZALEZ LS, SPENCER JP: Aminoglycosides: a practical review. Am Fam Physician 58: 1811-1820, 1988.

HUMES HD: Aminoglycoside nephrotoxicity. Kidney Int 33: 900-911, 1988.

IBRAHIM MIM, ABDELRAHIM HEA, AB RAHMAN AF: Cost evaluation of therapeutic drug monitoring of gentamicin at a teaching hospital in Malaysia. Pharm Pract 12: 372, 2014.

IHIS CR - Institute of Health Information and Statistics of the Czech Republic: Health Care in the Hl.m. Praha Region. 2015.

KAHLMETER G, DAHLAGER JI: Aminoglycoside toxicity - a review of clinical studies published between 1975 and 1982. J Antimicrob Chemother 13: 9-22, 1984.

KOHOUTOVÁ M, DEJMEK J, TŮMA Z, KUNCOVÁ J: Variability of mitochondrial respiration in relation to sepsisinduced multiple organ dysfunction. Physiol Res 67 (Suppl 4): S577-S592, 2018.

LENERT LA, KLOSTERMANN H, COLEMAN RW, LURIE J, BLASCHKE TF: Practical computer-assisted dosing for aminoglycoside antibiotics. Antimicrob Agents Chemother 36: 1230-1235, 1992.

LERNER SA, SELIGSOHN R, MATZ GJ: Comparative clinical studies of ototoxicity and nephrotoxicity of amikacin and gentamicin. Am J Med 62: 919-923, 1977.

LEVEY AS, DE JONG PE, CORESH J, EL NAHAS M, ASTOR BC, MATSUSHITA K, GANSEVOORT RT, KASISKE BL, ECKARDT KU: The definition, classification, and prognosis of chronic kidney disease: a KDIGO Controversies Conference report. Kidney Int 80: 17-28, 2011.

LEVI TM, SOUZA SP, DE MAGALHÃES JG, DE CARVALHO MS, CUNHA ALB, DANTAS JGA, DE O CRUZ MG, GUIMARÃES YLM, CRUZ CMS: Comparison of the RIFLE, AKIN and KDIGO criteria to predict mortality in critically ill patients. Rev Bras Ter Intensiva 25: 1-13, 2013.

LOPEZ-NOVOA JM, QUIROS Y, VICENTE L, MORALES AI, LOPEZ-HERNANDEZ FJ: New insights into the mechanism of aminoglycoside nephrotoxicity: an integrative point of view. Kidney Int 79: 33-45, 2011.

MATHEWS A, BAILIE GR: Clinical pharmacokinetics, toxicity and cost effectiveness analysis of aminoglycosides and aminoglycoside dosing services. J Clin Pharm Ther 12: 273-291, 1987.

NESBIT TW, SHERMOCK KM, BOBEK MB, CAPOZZI DL, FLORES PA, LEONARD MC, LONG JK, MILITELLO MA, WHITE DA, BARONE LD, GOLDMAN MP, KVANCZ DA: Implementation and pharmacoeconomic analysis of a clinical staff pharmacist practice model. Am J Health Syst Pharm 58: 784-790, 2001.

PINILLA J, SHAFRAN S, CONLY J: A utilization and cost-benefit analysis of an aminoglycoside kinetics monitoring service. Clin Investig Med Med Clin Exp 15: 8-17, 1992.

RYCHLÍČKOVÁ J, ŠALOUN J, GREGOROVÁ J: Evaluation of clinical pharmacists' interventions in the Czech Republic. Pharmacotherapy 36: 766-773, 2016.

SLAUGHTER RL, CAPPELLETTY DM: Economic impact of aminoglycoside toxicity and its prevention through therapeutic drug monitoring. Pharmacoeconomics 14: 385-394, 1998. 
STREETMAN DS, NAFZIGER AN, DESTACHE CJ, BERTINO AS: Individualized pharmacokinetic monitoring results in less aminoglycoside-associated nephrotoxicity and fewer associated costs. Pharmacotherapy 21: 443-451, 2001.

SLANǍ̌ O, PERLÍK F: Prof. RNDr. Dr.h.c. Jaroslav Květina, DrSc. celebrates his 85th birthday. Physiol Res 64 (Suppl 4): ix-X, 2015.

SVESKA KF, ROFFE BD, SOLOMON DK, HOFFMANN RP: Outcome of patients treated by an aminoglycoside pharmacokinetic dosing service. Am J Hosp Pharm 42: 2472-2478, 1985.

TOUW DJ, NEEF C, THOMSON AH, VINKS AA: Cost-effectiveness of therapeutic drug monitoring: a systematic review. Ther Drug Monit 27: 10-17, 2005.

VAN LENT-EVERS NA, MATHÔT RA, GEUS WP, VAN HOUT BA, VINKS A: Impact of goal-oriented and modelbased clinical pharmacokinetic dosing of aminoglycosides on clinical outcome: a cost-effectiveness analysis. Ther Drug Monit 21: 63-73, 1999.

VENISSE N, BOULAMERY A: Level of evidence for therapeutic drug monitoring of aminoglycosides. Therapie 66: 39-44, 2011.

WIESKE L, VAN HEST RM, WITTEVEEN E, VERHAMME C, SCHULTZ MJ, VAN SCHAIK IN, HORN J: Is gentamicin affecting the neuromuscular system of critically ill patients? Intensive Care Med 41: 727-728, 2015.

ZASKE DE, BOOTMAN JL, SOLEM LB, STRATE RG: Increased burn patient survival with individualized dosages of gentamicin. Surgery 91: 142-149, 1982. 